\title{
Plasma ghrelin, adiponectin and leptin levels in obese rats with type 2 diabetes mellitus after sleeve gastrectomy and gastric plication
}

\author{
LAURIAN STOICA $^{1,2^{*}}$, RAMONA GADEA $^{3 *}$, DAN-BOGDAN NAVOLAN $^{3}$, FULGER LAZAR $^{1}$, CIPRIAN DUTA $^{1,2}$, \\ DANA STOIAN $^{4}$, CRISTI TARTA ${ }^{1,2}$, FLAVIUS OLARU ${ }^{3}$, ALEXANDRU ISAIC $^{1,2}$ and AMADEUS DOBRESCU ${ }^{1,2}$ \\ ${ }^{1}$ Department of Surgery, 'Victor Babes' University of Medicine and Pharmacy Timisoara, 300041 Timisoara; \\ 22nd Department of Surgery, 'Pius Branzeu' Emergency Clinical County Hospital, 300723 Timisoara; \\ Departments of ${ }^{3}$ Obstetrics and Gynecology and ${ }^{4}$ Endocrinology, \\ 'Victor Babes' University of Medicine and Pharmacy Timisoara, 300041 Timisoara, Romania
}

Received September 9, 2020; Accepted October 9, 2020

DOI: 10.3892/etm.2021.9695

\begin{abstract}
The prevalence of obesity has increased in recent decades and has become a public health problem. In obesity patients the metabolism of almost all adipokines is markedly dysregulated. Studies regarding levels of ghrelin, leptin, and adiponectin after bariatric surgery reveal contradictory results. The purpose of the present study was to analyze modification of body weight and plasma levels of fasting glucose, ghrelin, adiponectin and leptin, in obese rats with T2DM after sleeve gastrectomy (SG), gastric plication (GP) and sham-operated (SO). Eighteen specimens where randomized to three weight-matched groups: Group SG underwent sleeve gastrectomy $(n=6)$, group GP underwent gastric plication $(n=6)$ and the control group SO underwent sham surgery $(n=6)$. Upon surgery a normal rat chow diet (Bio-Serv ${ }^{\circledR}$ product no. F4031) was fed to the rats until the end of the
\end{abstract}

Correspondence to: Professor Dan-Bogdan Navolan, Department of Obstetrics and Gynecology, 'Victor Babes' University of Medicine and Pharmacy Timisoara, 2 Eftimie Murgu Sq, 300041 Timisoara, Romania

E-mail: navolan@yahoo.com

Professor Fulger Lazar, Department of Surgery, 'Victor Babes' University of Medicine and Pharmacy Timisoara, 2 Eftimie Murgu Sq, 300041 Timisoara, Romania

E-mail: lazarfulger@yahoo.com

${ }^{*}$ Contributed equally

Abbreviations: DIO, diet-induced obesity; ELISA, enzyme-linked immunosorbent assay; GP, gastric plication; LGCP, laparoscopic greater curvature plication; LSG, laparoscopic sleeve gastrectomy; SG, sleeve gastrectomy; SO, sham-operated; T2DM, type 2 diabetes mellitus; GABA, $\gamma$-aminobutyric acid

Key words: experimental model, bariatric surgery techniques, weight loss, glucose level normalization, ghrelin, adiponectin, leptin experiment. Additional blood samples were harvested after 4 weeks. The results revealed that body mass decreased in the SG $(783.17 \pm 101.39$ vs. $658.33 \pm 86.57 \mathrm{~g} ; \mathrm{P}<0.0001)$ and the GP (781.33 \pm 103.12 vs. $702.33 \pm 84.06 \mathrm{~g} ; \mathrm{P}=0.004)$ rats after surgery. There were significant lower fasting glucose levels at 4 weeks postoperative in the SG group compared to the SO group $(83.1 \pm 12.81$ vs. $104.5 \pm 9.81 \mathrm{mg} / \mathrm{dl} ; \mathrm{P}=0.016)$. The same trend was observed in the GP group vs. the SO group $(86.7 \pm 11.43$ vs. $104.5 \pm 9.81 \mathrm{mg} / \mathrm{dl} ; \mathrm{P}=0.026)$. There was no difference regarding mean glucose levels between the SG group compared to the GP group ( $>>0.05)$. Plasma acylated ghrelin and leptin levels decreased four weeks after surgery compared to preoperative levels, while adiponectin levels increased four weeks after surgery in the SG and GP groups, respectively. The present study revealed that plasma glucose levels, ghrelin and leptin levels decreased after SG and GP, while adiponectin levels improved. This suggests that there may be hormonal contribution in weight loss.

\section{Introduction}

The prevalence of overweight and obesity has markedly increased in recent decades (1), and has become an important public health issue. Obesity is more often a crossover between metabolic syndrome, insulin resistance, type 2 diabetes mellitus (T2DM) and cardiovascular disease (2). It is the consequence of a positive energy balance, which can result from an increased energy intake and/or decreased energy expenditure (3). It may be described as a failure of the homeostatic mechanisms of the body to match energy intake with expenditure (3). The etiology of obesity is complex, involving genetic, environmental, and nutritional factors and some studies have linked obesity to oxidative stress and inflammation $(4,5)$. Research has revealed that obesity is associated with increased mortality and numerous complications including diabetes, heart disease, dementia and cancer, all of which have negative effects on the quality of life, work productivity, and healthcare costs (6).

Ghrelin, a 28-amino acid peptide named 'hunger hormone' which is involved in the regulation of body weight and energy 
balance, is produced mainly by the X/A cells of the gastric fundus. It is involved in appetite and food regulation, increases food intake and promotes fat accumulation (7).

Adipose tissue has a strong influence on whole-body glucose and lipid metabolism through its effects on major tissues and organs including the skeletal muscle, liver and brain (8). Adipocytes also secrete factors termed adipokines (9), and modulate body metabolism through secretion of endocrine and paracrine factors that modulate local immune cell cytokine secretion, endothelium blood flow and neuronal signaling to the brain (10). In obese patients the metabolism of almost all known adipokines is markedly dysregulated, being secreted in altered concentrations (11).

Adiponectin is a 244-amino acid protein secreted mainly by the adipose tissue (12), exhibits anti-diabetic, anti-inflammatory, and anti-atherogenic effects, and it also functions as an insulin sensitizer (12). Adiponectin also plays a central role in energy homeostasis through its action in the hypothalamus. Adiponectin causes weight loss (12).

Leptin (from the Greek word 'leptos' meaning thin) is an 'adipostat' that promotes energy expenditure $(3,13)$. Leptin is a 167 -amino acid peptide hormone encoded by the obesity gene and secreted by white adipocytes. Leptin is the satiety hormone, providing negative feedback to the hypothalamus to control appetite and energy expenditure $(3,13)$.

Bariatric surgery is currently considered to efficiently produce long-term body weight loss, improve comorbidities and improve quality of life in morbidly obese patients. Laparoscopic sleeve gastrectomy (LSG) was designed as a part of a two-stage procedure for morbidly obese patients, but gradually evolved as a standalone operation (14). Staple line leak and haemorrhage, although two major and difficult-to-treat postoperative complications, have been extensively investigated in present literature, mainly due to the related morbidity and mortality rates (15). To reduce serious complications, another restrictive technique was introduced: Laparoscopic greater curvature plication (LGCP) (16). LGCP and LSG both reduce gastric capacity, either by in-folding (LGCP) or removing (LSG) the greater curvature (17). Three mechanisms have been proposed for weight loss after LSG and GP: Mainly decreased capacity (restriction), decreased receptive relaxation (no fundus), and hormonal (decreased ghrelin levels) (18). It has been suggested that weight loss is accompanied by changes of the adipokine levels, as well (19).

While different studies on both humans and animal models are present in the literature regarding serum levels of ghrelin, leptin, and adiponectin after bariatric surgery, leading to contradictory and inconsistent results, they cause controversy regarding the anticipated results (20-22).

The purpose of the present experimental study was to evaluate changes of the plasma levels of ghrelin, adiponectin and leptin, in obese rats with T2DM after sleeve gastrectomy (SG) and gastric plication (GP).

\section{Materials and methods}

Experimental animals. We used eighteen male Wistar rats $(241.44 \pm 27.43 \mathrm{~g})$ from the Experimental Center of 'Pius Brinzeu' Center for Flap Surgery and Microsurgery, 'Victor Babeş' University of Medicine and Pharmacy Timişoara, which were reared in individual cages under controlled temperature $\left(21-23^{\circ} \mathrm{C}\right)$, humidity (50-55\%), and light (12-h light/dark cycle, lights turned on at 7 o'clock). All animals used for this study were healthy.

Study design. During the first phase of the experiment which lasted for 36 weeks, the rats had free access to DIO (diet-induced obesity) food (Bio-Serv ${ }^{\circledR}$ product no. F3282; Mouse Diet, High Fat, Fat Calories, 60\%; Bio-Serv) and tap water. Then, the Wistar rats were randomized into three weight-matched groups: The SG group that underwent sleeve gastrectomy $(n=6)$, the GP group that underwent gastric plication $(n=6)$ and the control group SO that underwent sham surgery $(n=6)$. Rats underwent gastric sleeve and plication surgery according to a previously detailed protocol (23). Upon completion of the surgical procedures, normal rat chow diet (Bio-Serv ${ }^{\circledR}$ product no. F4031; Bio-Serv) was fed to the rats until the end of the experiment. Additional blood tests were performed after these 4 weeks.

Surgical procedures and anesthesia protocol. The rats were kept fasting for $14 \mathrm{~h}$ overnight with access only to water, after which they were admitted into a $20 / 10 \mathrm{~cm}$ induction chamber for anesthesia, using Isoflurane ${ }^{\circledR}$ (Anesteran 99.9\%; Rompharm ${ }^{\mathrm{TM}}$ Company) $5 \%$ in a mixture with oxygen at a flow of $2.5 \mathrm{l} / \mathrm{min}$ debit based on spontaneous respiration. Once induction was achieved, isoflurane $1.5-2.2 \%$ in a mixture with oxygen was administered through a cone mask for rodents at a flow of 2-2.2 1/min. All surgeries were performed under sterile conditions. The rats were shaved and a povidone-iodine solution was applied to the skin.

The sleeve gastrectomy was performed by carrying out a 4-cm midline incision after which the gastrosplenic ligament was divided and the stomach was externalized. Using a $10 \mathrm{Ch}$ orogastric tube, the stomach was calibrated for all procedures. The greater curvature of the stomach, from the antrum to the fundus, was clamped using a vascular clamp in order to remove the main part of the corpus and fundus with a scalpel. The stomach was then closed with 5-0 non-absorbable polypropylene monofilament sutures (Premilene ${ }^{\mathrm{TM}}$; B. Braun Surgical S.A.) in two layers in a continuous fashion.

The gastric plication surgery was executed by performing a 4-cm midline incision, dividing the gastrosplenic ligament and externalizing the stomach. The surgery consisted of the imbrication of the greater gastric curvature over an orogastric tube applying a first row of extramucosal-interrupted stitches of 5-0 non-absorbable polypropylene monofilament sutures. The second row consisted of running suture lines of 5-0 non-absorbable polypropylene monofilament sutures.

For the SO group, after producing a $4-\mathrm{cm}$ upper midline incision, the stomach was externalized, manipulated, and then returned to the abdomen. The peritoneal cavity was rinsed with a saline solution and the abdominal wall was closed with running 3-0 polyglactin acid sutures. The skin was then sewed with 3-0 running intracutaneous absorbable multifilament-coated polyglactin sutures (Vicryl Ethicon ${ }^{\mathrm{TM}}$; Ethicon, Inc.; Johnson \& Johnson).

All animals were administered $5 \mathrm{ml}$ sterile warmed saline solution intraabdominally to avoid dehydration and allowed to recover spontaneously from anesthesia and surgery. 
Table I. Preoperative and postoperative values of body mass, fasting glucose, acylated ghrelin, adiponectin and leptin levels in plasma of rats from the three groups ( $\mathrm{SG}, \mathrm{GP}$ and $\mathrm{SO}$ ).

\begin{tabular}{lllccrl}
\hline \multicolumn{2}{c}{ Groups } & Body mass (g) & Fasting glucose (mg/dl) & Ghrelin (ng/ml) & Adiponectin (ng/ml) & Leptin (pg/ml) \\
\hline SG & Preop & $783.17 \pm 101.39$ & $152.33 \pm 33.60$ & $3.23 \pm 0.41$ & $86.66 \pm 23.00$ & $563.00 \pm 124.35$ \\
& Postop & $658.33 \pm 86.57$ & $83.16 \pm 12.70$ & $2.01 \pm 0.20$ & $115.83 \pm 16.89$ & $389.00 \pm 97.80$ \\
GP & Preop & $781.33 \pm 103.12$ & $150.00 \pm 34.74$ & $3.08 \pm 0.37$ & $74.50 \pm 17.87$ & $496.33 \pm 79.89$ \\
& Postop & $702.33 \pm 84.06$ & $86.66 \pm 11.46$ & $2.35 \pm 0.36$ & $107.00 \pm 15.97$ & $367.50 \pm 90.88$ \\
SO & Preop & $778.17 \pm 90.72$ & $146.50 \pm 39.32$ & $2.98 \pm 0.34$ & $113.16 \pm 38.32$ & $503.83 \pm 75.04$ \\
& Postop & $829.17 \pm 69.24$ & $104.50 \pm 9.97$ & $3.13 \pm 0.27$ & $101.00 \pm 20.95$ & $488.33 \pm 69.03$ \\
\hline
\end{tabular}

SG, sleeve gastrectomy; GP, gastric plication; SO, sham-operated; Preop, preoperative; Postop, postoperative.

Postoperative care. Prophylactic antibiotherapy consisting of ceftriaxone $(10 \mathrm{mg} / \mathrm{kg} /$ daily) was administered subcutaneously immediately after surgery and for the following three days, concomitantly with anti-inflammatories (meloxicam $1 \mathrm{mg} / \mathrm{kg} /$ daily) subcutaneously. During this period the rats were permitted access to a solution of Glucose $10 \%$. After $48 \mathrm{~h}$ from the surgical procedure, all rats were fed ad libitum, with normal chow diet (Bio-Serv ${ }^{\circledR}$ product no. F4031). All animals included in the study survived for the entire duration of the experiment. A calibrated Sartorius ${ }^{\mathrm{TM}}$ (Sartorious AG) scale was used to weigh the rats.

Blood collection and analysis. The fasting plasma glucose level from blood harvested from the tail of the rat, was determined using an ACCU-CHEK ${ }^{\circledR}$ glucometer (Roche Diagnostics). After 4 weeks a laparotomy was performed, blood was harvested from the inferior vena cava and measurement of plasmatic concentration of ghrelin and leptin as well as adipokine adiponectin by enzyme-linked immunosorbent assay (ELISA) technique was performed. Rat Acylated Ghrelin Express Elisa kit (cat. no. RA394062400R) and RAT leptin ELISA kit (cat. no. RD291001200R; both from BioVendor, Laboratorni Medicina S.A.) were used to determine ghrelin and respectively leptin plasma concentration. Plasma adiponectin concentration was measured using a rat ELISA Adiponectin kit (product code SK0010-0; Aviscera Bioscence, Inc.).

Statistical analysis. Results are presented as the means \pm SD. Data were analyzed using Microsoft Excel ${ }^{\mathrm{TM}}$ and Instat GraphPad Prism Software (GraphPad Software, Inc.). One-way analysis of variance ANOVA and Student's t-tests (both paired and unpaired) were used for comparing means between the groups. A P-value $<0.05$ was considered to indicate a statistically significant difference.

Ethical issues. The study was approved by the local Ethics Committee of the 'Pius Brinzeu' Clinical University Country Hospital Timisoara (no. 204/2020).

\section{Results}

Body mass and fasting plasma glucose levels in rats at the study onset. At the onset of the study the body mass of the eighteen rats was $241.44 \pm 27.43 \mathrm{~g}(\mathrm{~g})$. No significant statistical difference in body mass among the three groups of rats $[783.17 \pm 101.39 \mathrm{~g}$ (SG) vs. $781.33 \pm 103.12 \mathrm{~g}(\mathrm{GP})$ vs. $778.17 \pm 90.72 \mathrm{~g}$ (SO group), $(\mathrm{P}=0.87)]$ was present after 36 weeks of DIO feeding. In addition, the mean fasting glucose levels preoperatively for all groups was $149.6 \pm 33.86 \mathrm{mg} / \mathrm{dl}$. There was no statistical significance among the three groups $(\mathrm{P}>0.05)$ (Table I).

Decreasing body mass of rats after surgery. Four weeks after surgery body mass decreased in both categories of bariatric surgery groups: GS (783.17 \pm 101.39 vs. $658.33 \pm 86.57 \mathrm{~g}$; $\mathrm{P}<0.0001)$ and GP $(781.33 \pm 103.12$ vs. $702.33 \pm 84.06 \mathrm{~g}$; $\mathrm{P}=0.0004)$. No statistical difference regarding body weight was found four weeks postoperative between the GS and GP groups $(658.33 \pm 86.57$ vs. $702.33 \pm 84.06 \mathrm{~g} ; \mathrm{P}>005)$. An increase

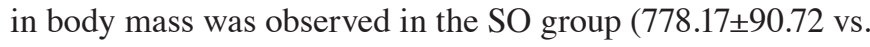
829.17 $\pm 69.24 \mathrm{~g} ; \mathrm{P}=0.004$ ) (Table I).

Decreasing fasting plasma glucose levels after surgery. There were significant lower fasting glucose levels at 4 weeks postoperative in the $\mathrm{SG}$ group compared to the $\mathrm{SO}$ group $(83.16 \pm 12.70$ vs. $104.50 \pm 9.97 \mathrm{mg} / \mathrm{dl} ; \mathrm{P}=0.016)$. The same trend was observed in the GP group vs. the SO group (86.66 \pm 11.46 vs. $104.5 \pm 9.97 \mathrm{mg} / \mathrm{dl} ; \mathrm{P}=0.01)$. There was no difference regarding mean glucose levels between the SG group compared to the GP group $(\mathrm{P}>0.05)$.

Changes of plasma ghrelin, adiponectin and leptin levels 1 month after surgery. Plasma acylated ghrelin levels decreased four weeks after surgery compared to preoperative levels in the SG group (3.23 \pm 0.41 vs. $2.01 \pm 0.2 \mathrm{ng} / \mathrm{ml} ; \mathrm{P}<0.05)$, GP group ( $3.08 \pm 0.37$ vs. $2.35 \pm 0.36 \mathrm{ng} / \mathrm{ml} ; \mathrm{P}<0.05)$ while a mild but non-significant (NS) increase was revealed in the SO group ( $2.98 \pm 0.34$ vs. $3.13 \pm 0.27 \mathrm{ng} / \mathrm{ml}$; NS). Furthermore, leptin levels decreased four weeks after surgery compared to preoperative levels in the $\mathrm{SG}$ group $(563.00 \pm 124.35$ vs. $389.00 \pm 97.8 \mathrm{pg} / \mathrm{ml} ; \mathrm{P}<0.05)$, and the GP group $(496.33 \pm 79.89$ vs. $367.50 \pm 90.88 \mathrm{pg} / \mathrm{ml} ; \mathrm{P}<0.05)$. A mild but NS decrease was revealed after surgery in the SO group (503.83 \pm 75.04 vs. $488.33 \pm 69.03 \mathrm{pg} / \mathrm{ml}$; NS), as well. Adiponectin levels increased four weeks after surgery in the SG group (86.66 \pm 23 vs. $115.83 \pm 16.89 \mathrm{ng} / \mathrm{ml} ; \mathrm{P}<0.05)$ and in the GP group $(74.5 \pm 17.87$ vs. $107 \pm 15.97 \mathrm{ng} / \mathrm{ml} ; \mathrm{P}<0.05)$, respectively. A NS decrease of 
adiponectin levels was revealed in the SO group $(113.16 \pm 38.3$ vs. $101 \pm 20.95 \mathrm{ng} / \mathrm{ml}$; NS) (Table I).

\section{Discussion}

The present study used the Wistar rat to reproduce the sleeve gastrectomy and gastric plication procedures that are used in humans in order to investigate the hormonal changes induced by surgery. Bariatric surgery interventions have become a popular method of weight reduction due to the numerous benefits they bestow to morbidly obese patients, such as long-term weight loss and improvement in the quality of life (24).

Four weeks after surgery, the positive effects of sleeve gastrectomy and gastric plication were observed regarding weight loss and an improvement of plasma glucose levels.

Ghrelin, an orexigenic hormone, mainly secreted by the gastric mucosa of the fundus increases its expression during fasting and is suppressed during the postprandial period. However, in obese individuals fasting plasma ghrelin is decreased by $30 \%$ and does not respond accordingly to food ingestion (25). Furthermore, in severely obese patients employing conservative methods of weight reduction will not satisfactorily modify ghrelin levels (26), yet bariatric surgery, such as sleeve gastrectomy decrease ghrelin levels more than any other type of surgery (27). Previous studies have revealed that ghrelin levels are reduced immediately after restrictive bariatric surgery or in weight-sTable patients $(28,29)$. The results of the present study revealed that acylated ghrelin levels significantly decreased after SG as well as GP, compared to the SO group.

It is also worth noting that ghrelin circulates in an inactive (des-acylated) and an active (acylated) form. While the des-acylated ghrelin is the most frequent form, accounting for $80-90 \%$ of the circulating levels, the acylated ghrelin is responsible for any endocrine activity (30). In the present study we were able to measure acylated ghrelin levels.

It has been revealed that adipose tissue has an important endocrine function under physiological and pathophysiological conditions. Disproportional accumulation of white adipose tissue in overweight and obese individuals is accompanied by a generalized change in the circulating levels of several adipokines (31).

In obese patients a dysregulation of metabolic parameters occurs such as worse lipid profiles, increased insulin resistance and a pro-inflammatory state (32). Moreover, adipokines have a strong contribution to the progression of obesity because they are secreted under altered conditions (32). It is still under debate whether adipokine deregulation is a cause or a consequence of metabolic alterations.

One such adipokine is adiponectin, having normally a hypoglycemic, insulin-sensitizing and anti-inflammatory effect. Initially, it was thought to be produced only by adipose tissue. However, subsequently it was demonstrated that adiponectin is expressed in other tissues including liver parenchyma cells human and murine, osteoblasts, myocytes, epithelial cells, and placental tissue (12). However, in obese individuals, adiponectin levels are severely reduced leading to deleterious metabolic results (33). Some studies even suggest that adiponectin may even serve as an early marker for diabetes mellitus because serum adiponectin levels are negatively associated with BMI in healthy individuals but are decreased in T2DM (34-37). Numerous studies have revealed that the adiponectin level is lower in the insulin-resistant stage and increased with improved insulin sensitivity after weight loss $(19,38-40)$. Bariatric surgery is known to markedly increase insulin sensitivity in severely obese adults (41). The present results revealed an increase in adiponectin serum levels after bariatric surgery, both after SG and GP, without any significant change in the SO group, results concordant with data from the literature (19).

Leptin, on the other hand, is an anorexigenic hormone secreted by the adipose tissue and its concentration is mostly correlated to total body fat mass (42), having an antagonist action to ghrelin. Since leptin improves peripheral insulin sensitivity by suppressing glucagon secretion, resistance to it leads to obesity (43). Following its release into the blood stream, leptin crosses the blood-brain barrier and binds itself to presynaptic $\gamma$-aminobutyric acid (GABA)ergic neurons where it produces its effects (3). Although leptin receptors are mostly present in the central nervous system in the afferent satiety centers of the hypothalamus, they are also expressed in peripheral organs, such as adipose tissues, skeletal muscles, pancreatic $\beta$ cells, and the liver, indicating endocrine, autocrine, and paracrine roles of leptin in energy regulation (3). Serum levels of leptin decrease in case of fasting, dieting, lipodystrophy or uncontrolled type 1 diabetes mellitus, which prompts stimulation of the hunger center of the brain (3).

Animal experiments are fundamental in understanding the most important mechanisms regarding obesity. According to Workman et al 'the current excellence of animal care standards are consistent with the experimental conditions needed when conducting research' (44).

The major limitations of this study are the small sample size that underwent surgery and the short postoperative follow-up time, but having in view it was an experimental study, group sizes are expected to be smaller.

In conclusion, SG and GP were revealed to lead to significant weight loss through a reduction in gastric capacity. The present study revealed that serum glucose levels, ghrelin and leptin levels decreased after SG and GP, while adiponectin levels improved. This may suggest that there is a hormonal contribution in weight loss. Further studies are required in order to disentangle the complex mechanisms regarding obesity, weight loss and hormonal changes.

\section{Acknowledgements}

Not applicable.

\section{Funding}

This study was partially supported by a grant from the 'Victor Babes' University of Medicine and Pharmacy Timisoara, Projects for young researchers-II-C3-TC-2015-OPTIM GALOP Acronym (Proiecte pentru tineri cercetatori programul II-C3-TC-2015 ACRONIM OPTIM GALOP).

\section{Availability of data and materials}

The datasets used and/or analyzed during the present study are available from the first author on reasonable request. 


\section{Authors' contributions}

LS, FL, CD, CT, AI and AD were involved in the conception of the study and experimental surgery. DBN, RG, FO and DS contributed to data collection, interpretation and statistical analysis. LS, FL, CD, CT, AI and AD wrote the manuscript. DBN, RG, FO and DS revised the manuscript for important intellectual content. All authors read and approved the final version of the manuscript.

\section{Ethics approval and consent to participate}

The present study meets the ethical guidelines, including adherence to the legal requirements of the study country. The study was approved by the local Ethics Committee of the 'Pius Brinzeu' Clinical University Country Hospital Timisoara (no. 204/2020), in compliance with the European Union laws.

\section{Patient consent for publication}

Not applicable.

\section{Competing interests}

The authors declare that they have no competing interests.

\section{References}

1. Ng M,Fleming T, Robinson M, Thomson B, Graetz N, Margono C Mullany EC, Biryukov S, Abbafati C, Abera SF, et al: Global, regional, and national prevalence of overweight and obesity in children and adults during 1980-2013: A systematic analysis for the Global Burden of Disease Study 2013. Lancet 384: 766-781, 2014.

2. Roberts CK, Hevener AL and Barnard RJ: Metabolic syndrome and insulin resistance: Underlying causes and modification by exercise training. Compr Physiol 3: 1-58, 2013.

3. Feng H, Zheng L, Feng Z, Zhao Y and Zhang N: The role of leptin in obesity and the potential for leptin replacement therapy. Endocrine 44: 33-39, 2013

4. Gu K, Li X, Xiang W and Jiang X: The relationship between serum copper and overweight/obesity: A Meta-analysis. Biol Trace Elem Res 194: 336-347, 2020.

5. Uranga RM and Keller JN: The complex interactions between obesity, metabolism and the brain. Front Neurosci 13: 513, 2019.

6. Kinlen D, Cody D and O'Shea D: Complications of obesity. QJM 111: 437-443, 2018.

7. Santiago-Fernández C, García-Serrano S, Tome M, Valdes S, Ocana-Wilhelmi L, Rodríguez-Canete A, Tinahones FJ, García-Fuentes E and Garrido-Sánchez L: Ghrelin levels could be involved in the improvement of insulin resistance after bariatric surgery. Endocrinol Diabetes Nut 64: 355-362, 2017.

8. Guilherme A, Virbasius JV, Puri V and Czech MP: Adipocyte dysfunctions linking obesity to insulin resistance and type 2 diabetes. Nat Rev Mol Cell Biol 9: 367-377, 2008.

9. Caron A, Lee S, Elmquist JK and Gautron L: Leptin and brain-adipose crosstalks. Nat Rev Neurosci 19: 153-165, 2018.

10. Guilherme A, Henriques F, Bedard AH, and Czech MP: Molecular pathways linking adipose innervation to insulin action in obesity and diabetes mellitus. Nat Rev Endocrinol 15: 207-225, 2019

11. Landecho MF, Tuero C, Valentí V, Bilbao I, de la Higuera M and Frühbeck G: Relevance of leptin and other adipokines in obesity-associated cardiovascular risk. Nutrients 11: 2664, 2019.

12. Achari AE and Jain SK: Adiponectin, a therapeutic target for obesity, diabetes, and endothelial dysfunction. Int J Mol Sci 18: 1321, 2017.
13. Mitrou P, Lambadiari V, Maratou E, Boutati E, Komesidou V, Papakonstantinou A, Raptis SA and Dimitriadis G: Skeletal muscle insulin resistance in morbid obesity: The role of interleukin-6 and leptin. Exp Clin Endocrinol Diabetes 119: 484-489, 2011.

14. Iannelli A, Schneck AS, Topart P, Carles M, Hébuterne X and Gugenheim J: Laparoscopic sleeve gastrectomy followed by duodenal switch in selected patients versus single-stage duodenal switch for superobesity: Case-control study. Surg Obes Relat Dis 9: 531-538, 2013.

15. Perivoliotis K, Sioka E, Katsogridaki G and Zacharoulis D: Laparoscopic gastric plication versus laparoscopic sleeve gastrectomy: An Up-to-Date systematic review and Meta-Analysis. J Obes 2018: 3617458, 2018.

16. Grubnik VV, Ospanov OB, Namaeva KA, Medvedev OV and Kresyun MS: Randomized controlled trial comparing laparoscopic greater curvature plication versus laparoscopic sleeve gastrectomy. Surg Endosc 30: 2186-2191, 2016.

17. Verdi D, Prevedello L, Albanese A, Lobba A and Foletto M: Laparoscopic Gastric Plication (LGCP) vs. Sleeve Gastrectomy (LSG): A Single Institution Experience. Obes Surg 25: 1653-1657, 2015.

18. Sethi P, Thillai M, Nain PS, Ahuja A, Aulakh N and Khurana P. Role of hunger hormone 'Ghrelin' in long-term weight loss following laparoscopic sleeve gastrectomy. Niger J Surg 24: 121-124, 2018.

19. Hosseinzadeh-Attar MJ, Golpaie A, Janani L and Derakhshanian H: Effect of weight reduction following bariatric surgery on serum visfatin and adiponectin levels in morbidly obese subjects. Obes Facts 6: 193-202, 2013.

20. Wroblewski E, Swidnicka-Siergiejko A, Hady HR, Luba M, Konopko M, Kurek K, Dadan J and Dabrowski A: Variation in blood levels of hormones in obese patients following weight reduction induced by endoscopic and surgical bariatric therapies. Cytokine 77: 56-62, 2016.

21. McCarty TR, Jirapinyo P and Thompson CC: Effect of Sleeve Gastrectomy on Ghrelin, GLP-1, PYY, and GIP Gut Hormones: A systematic review and Meta-Analysis. Ann Surg 272: 72-80, 2020.

22. Dobrescu A, Copaescu C, Zmeu B, Duta C, Bedreag OH, Stoica L, Tarta C, Rogobete AF and Lazar F: Ghrelin levels and hunger sensation after laparoscopic sleeve gastrectomy compared with laparoscopic greater curvature plication in obese patients. Clin Lab: May 1, 2020 (Epub ahead of print). doi: 10.7754/Clin. Lab.2019.191012.

23. Dobrescu A, Stoica L, Mituletu M, Isaic A, Duta C, Verdes G, Tarta C, Heghes A and Lazar F: Metabolic and weight changes after bariatric surgery in a rat model of induced type 2 diabetes mellitus and obesity. Rev Chim 69: 1030-1033, 2018.

24. Shah M, Simha V and Garg A: Review: Long-term impact of bariatric surgery on body weight, comorbidities, and nutritional status. J Clin Endocrinol Metab 91: 4223-4231, 2006.

25. Inui A, Asakawa A, Bowers CY, Mantovani G, Laviano A, Meguid MM and Fujimiya M: Ghrelin, appetite, and gastric motility: The emerging role of the stomach as an endocrine organ. FASEB J 18: 439-456, 2004.

26. Morpurgo PS, Resnik M, Agosti F, Cappiello V, Sartorio A and Spada A: Ghrelin secretion in severely obese subjects before and after a 3-week integrated body mass reduction program. J Endocrinol Invest 26: 723-727, 2003.

27. Kalinowski P, Paluszkiewicz R, Wróblewski T, Remiszewski P, Grodzicki M, Bartoszewicz Z and Krawczyk M: Ghrelin, leptin and glycemic control after sleeve gastrectomy vs. Roux-en-Y gastric bypass-results of a randomized clinical trial. Surg Obes Relat Dis 13: 181-188, 2016.

28. Fruhbeck G, Rotellar F, Hernandez-Lizoain JL, Gil MJ, Gómez-Ambrosi J, Salvador J and Cienfuegos JA: Fasting plasma ghrelin concentrations 6 months after gastric bypass are not determined by weight loss or changes in insulinemia. Obes Surg 14: 1208-1215, 2004

29. Terra X, Auguet T, Guiu-Jurado E, Berlanga A, OrellanaGavaldà JM, Hernández M, Sabench F, Porras JA, Llutart J, Martinez S, et al: Long-term changes in leptin, chemerin and ghrelin levels following different bariatric surgery procedures: Roux-en-Y gastric bypass and sleeve gastrectomy. Obes Surg 23: 1790-1798, 2013.

30. Delporte C: Recent advances in potential clinical application of ghrelin in obesity. J Obes 2012: 535624, 2012.

31. Forny-Germano L, De Felice FG and Vieira MNDN: The role of leptin and adiponectin in obesity-associated cognitive decline and Alzheimer's disease. Front Neurosci 12: 1027, 2019. 
32. Chen L, Deng H, Cui H, Fan J, Zuo Z, Deng J, Li Y, Wang X and Zhao L: Inflammatory responses and inflammation-associated diseases in organs. Oncotarget 9: 7204-7218, 2017.

33. Nigro E, Scudiero O, Monaco ML, Palmieri A, Mazzarella G Costagliola C, Bianco A and Daniele A: New insight into adiponectin role in obesity and obesity-related diseases. Biomed Res Int 2014: 658913, 2014.

34. Margoni A, Perrea DN, Vlachos I, Prokopaki G, Pantopoulou A, Fotis L, Kostaki M and Papavassiliou AG: Serum leptin, adiponectin and tumor necrosis factor- $\alpha$ in hyperlipidemic rats with/without concomitant diabetes mellitus. Mol Med 17: 36-40, 2011.

35. Kadowaki T, Yamauchi T, Kubota N, Hara K, Ueki K and Tobe K: Adiponectin and adiponectin receptors in insulin resistance, diabetes, and the metabolic syndrome. J Clin Invest 116: 1784-1792, 2006.

36. Hotta K, Funahashi T, Arita Y, Takahashi M, Matsuda M, Okamoto Y, Iwahashi H, Kuriyama H, Ouchi N, Maeda K, et al: Plasma concentrations of a novel, adipose-specific protein, adiponectin, in type 2 diabetic patients. Arterioscler Thromb Vasc Biol 20: 1595-1599, 2000.

37. Weyer C, Funahashi T, Tanaka S, Hotta K, Matsuzawa Y, Pratley RE and Tataranni PA: Hypoadiponectinemia in obesity and type 2 diabetes: close association with insulin resistance and hyperinsulinemia. J Clin Endocrinol Metab 86: 1930-1935, 2001

38. Faraj M, Havel PJ, Phélis S, Blank D, Sniderman AD and Cianflone K: Plasma acylation-stimulating protein, adiponectin, leptin, and ghrelin before and after weight loss induced by gastric bypass surgery in morbidly obese subjects. J Clin Endocrinol Metab 88: 1594-1602, 2003.
39. Guldstrand M, Ahrén B and Adamson U: Improved $\beta$-cell function after standardized weight reduction in severely obese subjects. Am J Physiol Endocrinol Metab 284: E557-E565, 2003.

40. Tschritter O, Fritsche A, Thamer C, Haap M, Shirkavand F, Rahe S, Staiger H, Maerker E, Häring H and Stumvoll M: Plasma adiponectin concentrations predict insulin sensitivity of both glucose and lipid metabolism. Diabetes 52: 239-243, 2003.

41. Kashyap SR, Gatmaitan P, Brethauer S and Schauer P: Bariatric surgery for type 2 diabetes: Weighing the impact for obese patients. Cleve Clin J Med 77: 468-476, 2010.

42. Friedman JM and Halaas JL: Leptin and the regulation of body weight in mammals. Nature 395: 763-770, 1998.

43. Munzberg H and Myers MG Jr: Molecular and anatomical determinants of central leptin resistance. Nat Neurosci 8: 566-570, 2005.

44. Workman P, Aboagye EO, Balkwill F, Balmain A, Bruder G, Chaplin DJ, Double JA, Everitt J, Farningham DA, Glennie MJ, et al: Guidelines for the welfare and use of animals in cancer research. Br J Cancer 102: 1555-1577, 2010.

This work is licensed under a Creative Commons Attribution-NonCommercial-NoDerivatives 4.0 International (CC BY-NC-ND 4.0) License. 